\title{
Usefulness of enhanced recovery after surgery protocol as compared with conventional perioperative care in gastric surgery
}

\author{
Takanobu Yamada · Tsutomu Hayashi • Haruhiko Cho • Takaki Yoshikawa • \\ Hideki Taniguchi $\cdot$ Ryoji Fukushima $\cdot$ Akira Tsuburaya
}

Received: 22 December 2010/Accepted: 18 April 2011/Published online: 15 May 2011

(C) The International Gastric Cancer Association and The Japanese Gastric Cancer Association 2011

\begin{abstract}
Background Radical gastrectomy for gastric cancer is among the most invasive procedures in gastrointestinal surgery. Several studies have found that an enhanced recovery after surgery (ERAS) protocol is useful in patients who undergo colorectal surgery, but its value in gastric surgery remains uncertain. The aim of this study was to assess the usefulness of an ERAS protocol for gastric surgery.

Methods We studied the clinical characteristics, oncological factors, surgical factors, and outcomes in patients who underwent elective radical gastrectomy for gastric cancer before and after the introduction of an ERAS protocol.

Results The first days of oral intake, oral intake recovery, flatus, and defecation were significantly earlier in the ERAS group $(n=91)$ than in the conventional care (CONV) group $(n=100)$. Maximum pain evaluated on a visual analog scale and the number of additional analgesics on demand were significantly less in the ERAS group than in the CONV group. The ratio of the postoperative body weight at 1 week to the preoperative body weight was
\end{abstract}

T. Yamada $(\bowtie) \cdot$ T. Hayashi · H. Cho · T. Yoshikawa .

A. Tsuburaya

Department of Gastrointestinal Surgery,

Kanagawa Cancer Center, 1-1-2 Nakao, Asahi-ku,

Yokohama, Kanagawa 241-0815, Japan

e-mail: takay0218@yahoo.co.jp

H. Taniguchi

Department of Anesthesiology, Kanagawa Cancer Center, 1-1-2 Nakao, Asahi-ku, Yokohama, Kanagawa 241-0815, Japan

R. Fukushima

Department of Surgery, Teikyo University School of Medicine,

2-11-1 Kaga, Itabashi-ku, Tokyo 173-8605, Japan significantly higher in the ERAS group than in the CONV group ( 0.95 vs. 0.94 , respectively, $P=0.01$ ).

Conclusion Our results suggest that the ERAS protocol is useful in patients who undergo elective radical gastrectomy.

Keywords Gastric cancer - Perioperative care · ERAS

\section{Introduction}

Surgery for gastric cancer remains a high-risk procedure with clinically significant postoperative stress, complications, and sequelae. Morbidity and mortality from radical gastrectomy range from 20 to $46 \%$ and 0.8 to $10 \%$, respectively [1-3]. Conventionally, patients scheduled to undergo gastrectomy fast for 1 day before the surgery and then receive intensive bowel preparation. Thoracic and upper abdominal surgical wounds are associated with the most severe pain. Patients usually have epigastric wound pain after the surgery. In addition, oral intake is not allowed for a long period after the surgery because it is anticipated that intraluminal pressure on the anastomosis would induce leakage.

Enhanced recovery after surgery (ERAS) programs have been proposed to maintain physiological function and thereby facilitate postoperative recovery. Several studies have shown that an ERAS protocol was useful in patients undergoing colorectal surgery [4-8], but its value in gastric surgery remains uncertain. ERAS programs consist of many elements, including preoperative education, preoperative carbohydrate loading, omission of bowel preparation, epidural analgesia without opioids, early postoperative enteral feeding, early mobilization of patients, and thromboprophylaxis. These elements are independent, but are directed 
toward the same goal: reducing surgical stress and optimizing recovery.

In June 2009, we revised our gastrectomy clinical pathway, referring to an ERAS protocol for colorectal resection [6-8]. In the present study, we compared postoperative outcomes between patients who received perioperative care according to our modified ERAS protocol and those who received conventional perioperative care, to evaluate the clinical relevance of the protocol in gastric surgery.

\section{Patients and methods}

\section{Patients}

We studied consecutive patients who underwent elective gastrectomy for gastric cancer at the Department of Gastrointestinal Surgery, Kanagawa Cancer Center, from November 2008 through December 2009. Patients who received conventional perioperative care underwent surgery from November 2008 through May 2009 (CONV group). Patients who received perioperative care according to the ERAS protocol underwent surgery from June 2009 through December 2009 (ERAS group).

All procedures were performed by the same team of surgeons. In principle, the patients diagnosed as being stage I preoperatively received laparoscopic surgery, and the others received open surgery. Anesthesia consisted of a combination of epidural analgesia (Th7-11) and general anesthesia. The amount of intravenous fluid used both during and after the operation was the same in the two groups. Steroids were not used in either group.

\section{Conventional perioperative care protocol}

Patients in the CONV group were allowed to have a liquid diet until lunch of the day before surgery and were allowed to drink the contents of two 500-ml plastic bottles of oral rehydration solution [OS- $1{ }^{\circledR}$; Fructlact injection (classified as a drug in Japan); Otsuka Pharmaceutical, Tokushima, Japan] until midnight of the day before surgery. Patients with gastric stenosis were not given OS- $1^{\circledR}$. Intensive bowel preparation $(10 \mathrm{ml} \quad 0.75 \%$ sodium picosulfate hydrate and $34 \mathrm{~g}$ magnesium citrate) was administered the day before surgery. One or two drains were always used for both total and distal gastrectomy. The nasogastric tube was removed on postoperative day (POD) 1. After surgery, a continuous thoracic epidural infusion of analgesics was given for 3 days. Additional analgesics were administered only when the patient had pain. On POD 3, patients were allowed to drink only water. Oral intake was started on POD 4, with the same step-by-step oral intake as in the
ERAS protocol. An antithrombotic agent was not administered prophylactically (Table 1).

\section{Modified ERAS protocol}

The modified ERAS protocol evaluated in the present study was developed by a team of surgeons and anesthesiologists working in close cooperation with a data safety monitoring committee (DSMC). A feasibility and safety audit by the DSMC was completed in September 2009, when 50 patients had been treated according to the ERAS protocol. Patients were allowed to eat until midnight of the day before surgery and were allowed to drink the contents of two 500-ml plastic bottles of OS- $1^{\circledR} 3 \mathrm{~h}$ before surgery. Patients with gastric stenosis were not given OS- $1^{\circledR}$. Mild bowel preparation $(1 \mathrm{~g}$ magnesium oxide and a New Lecicarbon ${ }^{\circledR}$ suppository [Zeria Pharmaceutical, Tokyo, Japan]) was administered the day before surgery. After the surgery, a continuous thoracic epidural infusion of analgesics was given for 2 days. The epidural catheter was removed $6 \mathrm{~h}$ before subcutaneous injection of an antithrombotic agent (enoxaparin sodium 2000 IU, twice daily). No drain was used in distal gastrectomy; one or two drains were used in total gastrectomy. The nasogastric tube was removed immediately after surgery. To prevent postoperative pain, a nonsteroidal anti-inflammatory drug (NSAID) (50 mg flurbiprofen axetil) was administered intravenously twice daily after the surgery until the resumption of oral intake. Patients were encouraged to sit out of bed for more than $6 \mathrm{~h}$ on postoperative day (POD) 1 . On POD 2, oral intake was started, beginning with water and an oral nutrition supplement $\left(250 \mathrm{ml}\right.$ Ensure Liquid $^{\circledR}$; Abbott Japan, Tokyo, Japan). After the resumption of oral intake, $100 \mathrm{mg}$ of acetaminophen was administered orally three times daily. The patients were encouraged to walk the length of the ward. On POD 3, the patients started to eat solid food, starting with rice gruel and soft food on POD 3 and advancing in three steps to regular food on POD 7. Discharge criteria were: adequate pain relief, soft food intake, return to preoperative mobility level, and normal laboratory data on POD 7 (Table 2).

\section{Data collection}

All data were retrieved from the patients' database and clinical records. The following data were extracted: sex, age, Eastern Cooperative Oncology Group (ECOG) performance status (PS), comorbidity (diabetes mellitus, hypertension, ischemic heart disease, respiratory disease, liver disease), smoking, American Society of Anesthesiologists Physical Status (ASAPS), tumor size, pathological $\mathrm{T}$ factor, pathological $\mathrm{N}$ factor, pathological stage, curability, approach, procedure, dissection level, reconstruction, splenectomy, operation time, bleeding, complications, 
Table 1 Timetable of CONV protocol

\begin{tabular}{|c|c|c|c|c|c|c|c|c|c|}
\hline Operative day & -1 & 0 & +1 & +2 & +3 & +4 & +5 & +6 & +7 \\
\hline Oral intake & $\begin{array}{l}\text { Liquid diet until } \\
\text { lunch; oral } \\
\text { hydration solution } \\
\left(\mathrm{OS}-1^{\circledR}\right) \text { until } \\
\text { midnight }\end{array}$ & No oral intake & $\rightarrow$ & $\rightarrow$ & $\begin{array}{l}\text { Drink only } \\
\text { water }\end{array}$ & & uid di & let (3 & $\begin{array}{l}\text { steps up to a } \\
\text { ery } 2 \text { days) }\end{array}$ \\
\hline Bowel preparation & $\begin{array}{l}10 \mathrm{ml} 0.75 \% \text { sodium } \\
\text { picosulfate hydrate } \\
\text { and } 34 \mathrm{~g} \\
\text { magnesium citrate }\end{array}$ & & & & & & & & \\
\hline \multirow[t]{3}{*}{$\begin{array}{l}\text { Anesthesia and } \\
\text { analgesics }\end{array}$} & & $\begin{array}{l}\text { Combination of } \\
\text { epidural analgesia } \\
\text { (TH7-11) and general } \\
\text { anesthesia during } \\
\text { surgery }\end{array}$ & & & & & & & \\
\hline & & $\begin{array}{l}\text { Continuous thoracic } \\
\text { epidural infusion of } \\
\text { analgesics after } \\
\text { surgery }\end{array}$ & $\rightarrow$ & $\rightarrow$ & $\begin{array}{l}\text { Remove } \\
\text { epidural } \\
\text { catheter }\end{array}$ & & & & \\
\hline & & $\begin{array}{l}\text { No anti-inflammatory } \\
\text { drug given routinely }\end{array}$ & $\rightarrow$ & $\rightarrow$ & $\rightarrow$ & $\rightarrow$ & $\rightarrow$ & $\rightarrow$ & $\rightarrow$ \\
\hline Drain and NGT & & $\begin{array}{l}\text { Always NGT and one or } \\
\text { two drains after both } \\
\text { total and distal } \\
\text { gastrectomy }\end{array}$ & $\begin{array}{l}\text { Remove } \\
\text { NGT }\end{array}$ & & $\begin{array}{l}\text { Remove } \\
\text { drain(s) }\end{array}$ & & & & \\
\hline ADL & & & $\begin{array}{l}\text { Mobilization } \\
\text { on bed }\end{array}$ & $\begin{array}{l}\text { Encouraged } \\
\text { to sit out } \\
\text { of bed }\end{array}$ & $\begin{array}{l}\text { Encouraged } \\
\text { to walk the } \\
\text { length of } \\
\text { the ward }\end{array}$ & $\rightarrow$ & $\rightarrow$ & $\rightarrow$ & $\rightarrow$ \\
\hline Thromboprophylaxis & & & None & $\rightarrow$ & $\rightarrow$ & $\rightarrow$ & $\rightarrow$ & $\rightarrow$ & $\rightarrow$ \\
\hline $\begin{array}{l}\text { X-ray and blood } \\
\text { examination }\end{array}$ & & O & $\bigcirc$ & & & & & & $\begin{array}{l}\text { (check } \\
\text { discharge } \\
\text { criteria) }\end{array}$ \\
\hline
\end{tabular}

$C O N V$ conventional care, $N G T$ nasogastric tube, $A D L$ activities of daily life, $\rightarrow$ continue, $\bigcirc$ check these examination

mortality, accomplishment of clinical pathway, first day of walking, first day of oral intake, day of oral intake recovery, first day of flatus, first day of defecation, allowed day of discharge, postoperative hospital stay, maximum pain on a visual analog scale, the number of additional doses of analgesics, and the ratio of postoperative body weight (1 week, 1 month, and 3 months after surgery) to preoperative body weight. Pathological findings were categorized according to the 2nd English edition of the Japanese classification of gastric carcinoma [9]. Complications were defined as grade 2 or higher complications, according to the Clavien-Dindo classification, within 30 days after surgery [10]. Oral intake recovery was defined as the ability to ingest more than $50 \%$ of a second-step meal.

\section{Statistical analysis}

Data were analyzed on an intention-to-treat basis. The ERAS protocol was compared with conventional perioperative care by using the $\chi^{2}$ test for binary outcomes and the Mann-Whitney $U$-test for continuous outcomes. All statistical analyses were performed using the Dr. SPSS II program, version 11.0.1J for Windows (SPSS, Chicago, IL, USA). Two-sided $P$ values were calculated, and a difference was considered statistically significant at $P<0.05$. Continuous data are expressed as medians (ranges).

\section{Results}

One hundred patients received conventional perioperative care, and ninety-one patients were treated according to the ERAS protocol.

\section{Comparison of characteristics between CONV group and ERAS group}

There were no significant differences between the CONV group and ERAS group with respect to sex, age, PS, comorbidity, smoking, or ASAPS. However, the ERAS 
Table 2 Timetable of ERAS protocol

\begin{tabular}{|c|c|c|c|c|c|c|c|c|c|}
\hline Operative day & -1 & 0 & +1 & +2 & +3 & +4 & +5 & +6 & +7 \\
\hline Oral intake & $\begin{array}{l}\text { Normal diet } \\
\text { until midnight }\end{array}$ & $\begin{array}{l}\text { Oral hydration solution }\left(\mathrm{OS}-1^{\circledR}\right) \\
3 \mathrm{~h} \text { before surgery }\end{array}$ & & $\begin{array}{l}\text { Drink water and an } \\
\text { oral nutrition } \\
\text { supplement } \\
\left(\text { Ensure Liquid }^{\circledR}\right)\end{array}$ & $\begin{array}{r}\text { Liqu } \\
\text { die }\end{array}$ & iid di & $\begin{array}{l}\text { iet }(3 \mathrm{st} \\
\text { ery } 2 \mathrm{da}\end{array}$ & $\begin{array}{l}\text { teps } \\
\text { ays) }\end{array}$ & up to a soft \\
\hline Bowel preparation & $\begin{array}{l}1 \text { g magnesium } \\
\text { oxide and a } \\
\text { New } \\
\text { Lecicarbon }{ }^{\circledR} \\
\text { suppository }\end{array}$ & & & & & & & & \\
\hline \multirow[t]{3}{*}{$\begin{array}{l}\text { Anesthesia and } \\
\text { analgesics }\end{array}$} & & $\begin{array}{l}\text { Combination of epidural } \\
\text { analgesia (TH7-11) and } \\
\text { general anesthesia during } \\
\text { surgery }\end{array}$ & & & & & & & \\
\hline & & $\begin{array}{l}\text { Continuous thoracic epidural } \\
\text { infusion of analgesics after } \\
\text { surgery }\end{array}$ & $\rightarrow$ & $\begin{array}{l}\text { Remove epidural } \\
\text { catheter }\end{array}$ & & & & & \\
\hline & & $\begin{array}{l}\text { Nonsteroidal anti-inflammatory } \\
\text { drug intravenously after } \\
\text { surgery twice daily }\end{array}$ & $\rightarrow$ & $\begin{array}{l}\text { Acetaminophen } \\
\text { three times daily, } \\
\text { orally }\end{array}$ & $\rightarrow$ & $\rightarrow$ & $\rightarrow$ & & \\
\hline Drain and NGT & & $\begin{array}{l}\text { No drain in distal gastrectomy, } \\
\text { one or two drains in total } \\
\text { gastrectomy. NGT was } \\
\text { removed immediately after } \\
\text { surgery }\end{array}$ & & Remove drain(s) & & & & & \\
\hline ADL & & & $\begin{array}{l}\text { Encouraged } \\
\text { to sit out of } \\
\text { bed for } \\
\text { more than } \\
6 \mathrm{~h}\end{array}$ & $\begin{array}{l}\text { Encouraged to } \\
\text { walk the length } \\
\text { of the ward }\end{array}$ & $\rightarrow$ & $\rightarrow$ & $\rightarrow$ & $\rightarrow$ & $\rightarrow$ \\
\hline Thromboprophylaxis & & & None & $\begin{array}{l}\text { Subcutaneous } \\
\text { injection of } \\
\text { antithrombotic } \\
\text { agent } \\
\text { (enoxaparin } \\
\text { sodium) }\end{array}$ & $\rightarrow$ & $\rightarrow$ & None & $\rightarrow$ & $\rightarrow$ \\
\hline $\begin{array}{l}\text { X-ray and blood } \\
\text { examination }\end{array}$ & & $\bigcirc$ & $\bigcirc$ & & & & & & $\begin{array}{l}\text { (Check } \\
\text { discharge } \\
\text { criteria) }\end{array}$ \\
\hline
\end{tabular}

ERAS enhanced recovery after surgery, $N G T$ nasogastric tube, $A D L$ activities of daily life, $\rightarrow$ continue, $\bigcirc$ check these examination

Table 3 Comparison of characteristics between CONV group and ERAS group

CONV conventional care, ERAS enhanced recovery after surgery, $P S$ Eastern Cooperative Oncology Group performance status, $D M$ diabetes mellitus, $H T$ hypertension, $I H D$ ischemic heart disease, ASAPS American Society of Anesthesiologists Physical Status

\begin{tabular}{llll}
\hline & $\begin{array}{l}\text { CONV group } \\
(n=100)\end{array}$ & $\begin{array}{l}\text { ERAS group } \\
(n=91)\end{array}$ & $P$ value \\
\hline Sex (M/F) & $72 / 28$ & $62 / 29$ & 0.34 \\
Age (years) & $65.0(29-84)$ & $67.0(42-84)$ & 0.10 \\
PS (0/1/2) & $90 / 7 / 3$ & $80 / 11 / 0$ & 0.13 \\
DM (-/+) & $92 / 8$ & $77 / 14$ & 0.09 \\
HT (-/+) & $69 / 31$ & $65 / 26$ & 0.42 \\
IHD (-/+) & $99 / 1$ & $89 / 2$ & 0.46 \\
Respiratory disease (-/+) & $86 / 14$ & $77 / 13$ & 0.55 \\
Liver disease (-/+) & $94 / 6$ & $88 / 3$ & 0.30 \\
Smoking (-/+) & $79 / 21$ & $73 / 18$ & 0.55 \\
ASAPS (0/1) & $40 / 59$ & $32 / 59$ & 0.28 \\
\hline
\end{tabular}


Table 4 Comparison of oncological factors and surgical factors between the CONV group and ERAS group
CONV conventional care, ERAS enhanced recovery after surgery, lap laparoscopyassisted, $T G$ total gastrectomy, $D G$ distal gastrectomy, $B 1$ Billroth-I reconstruction, $B 2$ Billroth-II reconstruction, $R Y$ Roux-en-Y reconstruction

\begin{tabular}{|c|c|c|c|}
\hline & $\begin{array}{l}\text { CONV group } \\
(n=100)\end{array}$ & $\begin{array}{l}\text { ERAS group } \\
(n=91)\end{array}$ & $P$ value \\
\hline Tumor size (mm) & $35.0(0-190)$ & $39.0(0-200)$ & 0.75 \\
\hline $\mathrm{T}$ factor $(1 / \geq 2)$ & $50 / 50$ & $52 / 39$ & 0.24 \\
\hline $\mathrm{N}$ factor $(0 / 1 / 2)$ & $58 / 24 / 18$ & $61 / 15 / 15$ & 0.38 \\
\hline Stage $(1 / 2 / 3 / 4)$ & $58 / 14 / 18 / 10$ & $59 / 17 / 7 / 8$ & 0.40 \\
\hline Curability (A/B/C) & $65 / 23 / 12$ & $68 / 16 / 7$ & 0.36 \\
\hline Approach (open/lap) & $57 / 43$ & $43 / 48$ & 0.12 \\
\hline Procedure (TG/DG) & $52 / 48$ & $57 / 34$ & 0.21 \\
\hline Dissection (D0-1/D2) & $59 / 41$ & $54 / 37$ & 1.00 \\
\hline Reconstruction (B1/B2/RY) & $42 / 6 / 52$ & $45 / 3 / 43$ & 0.32 \\
\hline Splenectomy $(-/+)$ & $86 / 14$ & $78 / 13$ & 0.57 \\
\hline Operation time $(\min )$ & $206.0(106-369)$ & $177.0(80-329)$ & 0.00 \\
\hline Bleeding (ml) & $102.5(0-1240)$ & $80.0(0-1620)$ & 0.10 \\
\hline Complications (Clavien-Dindo grade $0-1 / \geq 2$ ) & $88 / 12$ & $84 / 7$ & 0.47 \\
\hline Mortality $(-/+)$ & $100 / 0$ & $91 / 0$ & 1.00 \\
\hline
\end{tabular}

Table 5 Comparison of postoperative outcomes between CONV group and ERAS group

\begin{tabular}{|c|c|c|c|}
\hline & CONV group $(n=100)$ & ERAS group $(n=91)$ & $P$ value \\
\hline Accomplish clinical pathway & $96.0 \%(96 / 100)$ & $94.5 \%(86 / 91)$ & 0.74 \\
\hline First day of walking & $2(1-8)$ & $2(1-3)$ & 0.43 \\
\hline First day of oral intake & $4(2-17)$ & $2(1-6)$ & $<0.01$ \\
\hline Day of oral intake recovery & $7(5-34)$ & $6(3-45)$ & $<0.01$ \\
\hline First day of flatus & $3(2-12)$ & $2(1-5)$ & 0.01 \\
\hline First day of defecation & $6(2-12)$ & $4(1-66)$ & $<0.01$ \\
\hline Allowed day of discharge & $7(8-84)$ & $7(4-46)$ & 0.50 \\
\hline Postoperative hospital stay (days) & $9(8-86)$ & $9(7-47)$ & 0.98 \\
\hline Maximum pain on visual analog scale & $5(1-10)$ & $4(0-10)$ & 0.05 \\
\hline Number of additional doses of analgesics & $10(0-43)$ & $3(0-50)$ & $<0.01$ \\
\hline The ratio of postoperative ( 1 week) to preoperative body weight & $0.94(0.88-1.09)$ & $0.95(0.87-1.03)$ & $\mathbf{0 . 0 1}$ \\
\hline The ratio of postoperative ( 1 month) to preoperative body weight & $0.92(0.83-1.09)$ & $0.93(0.72-1.24)$ & 0.69 \\
\hline The ratio of postoperative ( 3 months) to preoperative body weight & $0.89(0.77-1.11)$ & $0.89(0.59-1.02)$ & 0.40 \\
\hline
\end{tabular}

$C O N V$ conventional care, ERAS enhanced recovery after surgery

Items in boldface indicate significant differences between the groups

group tended to be older, have a worse PS, and have a higher prevalence of diabetes mellitus (Table 3).

Comparison of oncological factors and surgical factors between the CONV group and ERAS group

There were no significant differences between the CONV group and the ERAS group with respect to tumor size, pathological $\mathrm{T}$ factor, pathological $\mathrm{N}$ factor, pathological stage, curability, approach, procedure, dissection level, reconstruction, splenectomy, bleeding, or complications. The only difference was that operation time was shorter in the ERAS group than in the CONV group. Morbidity did not differ significantly between the groups (Table 4). Complications in the CONV group were gastrointestinal obstruction $(n=1)$, intra-abdominal abscess $(n=1)$, biliary tract infection $(n=1)$, postoperative bleeding $(n=1)$, anastomotic leakage $(n=2)$, postoperative anemia $(n=3)$, and pancreatic fistula $(n=3)$. Complications in the ERAS group were ascites $(n=1)$, pancreatic fistula $(n=1)$, anastomotic leakage $(n=1)$, postoperative bleeding on POD 1 before administration of an antithrombotic agent $(n=1)$, and gastrointestinal obstruction $(n=3)$.

\section{Comparison of postoperative outcomes between CONV} group and ERAS group

There were no significant differences between the CONV group and the ERAS group in accomplishment of the 
clinical pathway, the first day of walking, the allowed day of discharge, or the postoperative hospital stay. However, the first days of oral intake, oral intake recovery, flatus, and defecation were significantly earlier in the ERAS group than in the CONV group. Maximum pain on a visual analog scale and the number of additional doses of analgesics required were significantly less in the ERAS group than in the CONV group. The ratio of postoperative to preoperative body weight was significantly higher in the ERAS group than in the CONV group 1 week after surgery, but the ratio did not differ between the groups at 1 or 3 months (Table 5).

\section{Discussion}

In the present study, the ERAS protocol as a whole was novel in gastric surgery, although the individual components are in practice at some Japanese high-volume centers. In accordance with the DSMC's suggestions and audit, the ERAS protocol was evaluated by comparison with the CONV protocol, in a group comprised of patients who underwent surgery and were followed for the same length of time as the ERAS group (7 months) as a historical control before the introduction of the ERAS protocol.

Clinical characteristics, oncological factors, and surgical factors, apart from operation time, did not differ significantly between the ERAS group and the CONV group. Operation time was shorter in the ERAS group than in the CONV group. However, the effect of a reduction of only $30 \mathrm{~min}$ in median operation time on postoperative outcomes was unclear. In the Japan Clinical Oncology Group (JCOG) 9501 trial comparing D2 versus D2 and extended para-aortic lymphadenectomy, the median operation time was 63 min longer in the latter group, without any difference in morbidities [11].

Avoidance of a full stomach is much more important in gastric resection than in colorectal resection, not only for the prevention of aspiration at the induction of anesthesia, but also for ensuring intraoperative maneuverability of the stomach and decreasing the risk of surgical-site infection. In the ERAS protocol for colorectal resection, patients receive $12.5 \%$ carbohydrate loading [12]. We used OS $-1^{\circledR}(2.5 \%$ carbohydrate) for preoperative rehydration before surgery because of its rapid clearance from the stomach. Taniguchi et al. [13] reported that the volume of esophageal-pharyngeal fluid and gastric fluid following the induction of anesthesia was only $6.03 \pm-9.14 \mathrm{ml}$ and that no adverse event or adverse reaction occurred after preoperative OS- $1^{\circledR}$ loading. But $12.5 \%$ carbohydrate clearance from the stomach is unclear. Further study is needed to determine whether OS- ${ }^{\circledR}$ is effective as a carbohydrate loading and whether $12.5 \%$ carbohydrate is safe for gastric surgery.
No abdominal drain was used routinely in the patients in the ERAS group who underwent distal gastrectomy. There were no complications associated with drains in either of the groups. Alvarez Uslar et al. [14], in a study in Chile, reported that operative morbidity and hospital stay were significantly higher in the group of patients who underwent total gastrectomy with abdominal drains than in the group of patients without drains. However, we refrained from abolishing the use of drains for total gastrectomies at this time, since the degree of lymph node dissection is more extensive in Japan than in the West, and often calls for splenectomy, possibly leading to a higher risk for of surgical-site infection. The use of drains after total gastrectomy continues to be an issue for debate in the future development of the ERAS program.

Bowel movement recovery (i.e., the first days of oral intake, oral intake recovery, flatus, and defecation) was earlier in the ERAS group than in the CONV group in our study. Wang et al. [15] reported that the first day of flatus after gastric surgery was earlier in patients who received fast-track surgery care than in those who received conventional care (3 vs. 4 days). Teeuwen et al. [5] found that oral intake in their ERAS group was higher than that in the conventional group after colorectal surgery. Prolonged perioperative fasting, preoperative bowel preparation, and nasogastric tube intubation are likely to induce nausea and delay bowel-function recovery. Previous studies have reported that the patients without a postoperative nasogastric tube recovered postoperative bowel movement earlier than the patients with one, and that routine postoperative nasogastric tube intubation is unnecessary after an elective operation [16, 17]. On the other hand, complications potentially caused by a short fasting period, such as aspiration pneumonia or anastomotic leakage, did not increase in our ERAS group, and accomplishment of the clinical pathway did not differ between our groups. Suehiro et al. [18] reported that early feeding 2 days after gastrectomy was safe, with no increase in morbidity.

In our study, the epidural catheter was removed earlier in the ERAS group than in the CONV group, in accordance with an antithrombotic agent being administered prophylactically on POD 2. Moreover, an NSAID and acetaminophen were used as baseline analgesics throughout the postoperative course in the ERAS group. Consequently, maximum pain assessed on a visual analog scale and the number of additional doses of analgesics were significantly less in the ERAS group. It was not clear whether the total dose of analgesics (baseline plus additional analgesics) was different between the two groups. Baseline NSAID analgesics could be sufficient for the prevention of postoperative pain regardless of the short-term action of the epidural analgesic. Less pain facilitated early mobilization. Bed rest not only increases muscle loss and insulin resistance, but 
also decreases pulmonary function and tissue oxygenation [19].

According to the National Comprehensive Cancer Network (NCCN) guideline, after surgery for cancer, all in-patients and out-patients are recommended to receive prophylactic anticoagulation therapy for up to 4 weeks after the surgery [20]. Also, the American Society of Clinical Oncology (ASCO) guidelines recommend that all patients undergoing major surgical intervention should be considered for thromboprophylaxis, starting as early as possible after the surgery and continuing for at least 7-10 days unless there is a contraindication [21]. To minimize the risk of epidural hematoma at the time of removing an epidural catheter, we do not start thromboprophylaxis on POD 1 before the removal of the epidural catheter on POD 2. There were no thromboembolic events or epidural hematomas in either of our groups, and there was no postoperative bleeding associated with thromboprophylaxis. Jeong et al. [22] reported that perioperative low-molecular-weight heparin as thromboprophylaxis significantly increased the risk of bleeding after gastric surgery. Therefore, an optimal thromboprophylaxis regimen of should be determined in further trials.

The day when discharge was allowed and the duration of the postoperative hospital stay did not differ between our ERAS group and the CONV group. This lack of a difference was attributed to the discharge criteria and the Japanese Diagnosis Procedure Combination-based Payment System (DPC). Because laboratory testing was performed on POD 7 in both groups, the mean day of discharge did not differ significantly. Wang et al. [15] reported that the postoperative hospital stay after gastric surgery was shorter in patients who received fast-track surgery care than in those who received conventional care.

In our study, the ratio of the postoperative body weight at 1 week to the preoperative body weight was higher in the ERAS group than that in the CONV group, despite the relatively higher proportion of elderly patients in the former group. Holte et al. [23] reported that preoperative bowel preparation caused dehydration and fluid electrolyte abnormalities, particularly in elderly patients. We attribute the prompter body weight recovery in the ERAS group not only to less postoperative muscle loss and fat loss, but also to their well-hydrated status during the perioperative period.

In conclusion, our results suggest that the ERAS protocol described here is useful in patients who undergo elective gastrectomy. Further study is needed to confirm the effectiveness of this protocol in terms of the recovery of the patients and to decide whether or not to include other components of the ERAS program.
Acknowledgments This study was supported in part by a Grant-inAid from the Kanagawa Health Foundation.

\section{References}

1. Bonenkamp JJ, Hermans J, Sasako M, van de Velde CJ, Welvaart $\mathrm{K}$, Songun I, et al. Extended lymph-node dissection for gastric cancer. N Engl J Med. 1999;340:908-14.

2. Cuschieri A, Fayers P, Fielding J, Craven J, Bancewicz J, Joypaul $\mathrm{V}$, et al. Postoperative morbidity and mortality after D1 and D2 resections for gastric cancer: preliminary results of the MRC randomised controlled surgical trial. The Surgical Cooperative Group. Lancet. 1996;347:995-9.

3. Sasako M, Sano T, Yamamoto S, Kurokawa Y, Nashimoto A, Kurita A, Hiratsuka M, et al. D2 lymphadenectomy alone or with para-aortic nodal dissection for gastric cancer. N Engl J Med. 2008;359:453-62.

4. Varadhan KK, Neal KR, Dejong CH, Fearon KC, Ljungqvist O, Lobo DN. The enhanced recovery after surgery (ERAS) pathway for patients undergoing major elective open colorectal surgery: a meta-analysis of randomized controlled trials. Clin Nutr. 2010;29:434-40.

5. Teeuwen PH, Bleichrodt RP, Strik C, Groenewoud JJ, Brinkert $\mathrm{W}$, van Laarhoven $\mathrm{CJ}$, et al. Enhanced recovery after surgery (ERAS) versus conventional postoperative care in colorectal surgery. J Gastrointest Surg. 2010;14:88-95.

6. King PM, Blazeby JM, Ewings P, Longman RJ, Kipling RM, Franks PJ, et al. The influence of an enhanced recovery programme on clinical outcomes, costs and quality of life after surgery for colorectal cancer. Colorectal Dis. 2006;8:506-13.

7. Fearon KC, Luff R. The nutritional management of surgical patients: enhanced recovery after surgery. Proc Nutr Soc. 2003;62:807-11.

8. Mohn AC, Bernardshaw SV, Ristesund SM, Hovde Hansen PE, Røkke O. Enhanced recovery after colorectal surgery. Results from a prospective observational two-centre study. Scand J Surg. 2009;98:155-9.

9. Japanese Gastric Cancer Association. Japanese classification of gastric carcinoma, 2nd English edition. Gastric Cancer 1998;1:10-24.

10. Dindo D, Demartines N, Clavien PA. Classification of surgical complications: a new proposal with evaluation in a cohort of 6336 patients and results of a survey. Ann Surg. 2004;240: 205-13.

11. Sano T, Sasako M, Yamamoto S, Nashimoto A, Kurita A, Hiratsuka M, et al. Gastric cancer surgery: morbidity and mortality results from a prospective randomized controlled trial comparing D2 and extended para-aortic lymphadenectomy-Japan Clinical Oncology Group study 9501. J Clin Oncol. 2004;22:2767-73.

12. Lassen K, Soop M, Nygren J, Cox PB, Hendry PO, Spies C, et al. Consensus review of optimal perioperative care in colorectal surgery: Enhanced Recovery After Surgery (ERAS) Group recommendations. Arch Surg. 2009;144:961-9.

13. Taniguchi H, Sasaki T, Fujita H, Takamori M, Kawasaki R, Momiyama Y, et al. Preoperative fluid and electrolyte management with oral rehydration therapy. J Anesth. 2009;23:222-9.

14. Alvarez Uslar R, Molina H, Torres O, Cancino A. Total gastrectomy with or without abdominal drains. A prospective randomized trial. Rev Esp Enferm Dig. 2005;97:562-9.

15. Wang D, Kong Y, Zhong B, Zhou X, Zhou Y. Fast-track surgery improves postoperative recovery in patients with gastric cancer: a randomized comparison with conventional postoperative care. J Gastrointest Surg. 2010;14:620-7. 
16. Carrère N, Seulin P, Julio CH, Bloom E, Gouzi JL, Pradère B. Is nasogastric or nasojejunal decompression necessary after gastrectomy? A prospective randomized trial. World J Surg. 2007; 31:122-7.

17. Yoo CH, Son BH, Han WK, Pae WK. Nasogastric decompression is not necessary in operations for gastric cancer: prospective randomised trial. Eur J Surg. 2002;168:379-83.

18. Suehiro T, Matsumata T, Shikada Y, Sugimachi K. Accelerated rehabilitation with early postoperative oral feeding following gastrectomy. Hepatogastroenterology. 2004;51:1852-5.

19. Soop M, Carlson GL, Hopkinson J, Clarke S, Thorell A, Nygren $\mathrm{J}$, et al. Randomized clinical trial of the effects of immediate enteral nutrition on metabolic responses to major colorectal surgery in an enhanced recovery protocol. Br J Surg. 2004; 91:1138-45.
20. Wagman LD, Baird MF, Bennett CL, Bockenstedt PL, Cataland SR, Fanikos J, et al. Venous thromboembolic disease. NCCN. Clinical practice guidelines in oncology. J Natl Compr Canc Netw. 2008;6:716-53.

21. Lyman GH, Khorana AA, Falanga A, Clarke-Pearson D, Flowers C, Jahanzeb M, et al. American Society of Clinical Oncology guideline: recommendations for venous thromboembolism prophylaxis and treatment in patients with cancer. J Clin Oncol. 2007;25:5490-505.

22. Jeong O, Ryu SY, Park YK, Kim YJ. The effect of low molecular weight heparin thromboprophylaxis on bleeding complications after gastric cancer surgery. Ann Surg Oncol. 2010;17:2363-9.

23. Holte K, Nielsen KG, Madsen JL, Kehlet H. Physiologic effects of bowel preparation. Dis Colon Rectum. 2004;47:1397-402. 